\title{
Simulation of synthesis of cluster-assembled nanostructured materials
}

\author{
M.S.Byshkin, A.S.Bakai, N.P.Lazarev, A.A.Turkin \\ National Science Center Kharkiv Institute of Physics and Technology \\ 1 Akademichna Str., 61108 Kharkiv, Ukraine
}

Received January 29, 2003

\begin{abstract}
A model is described to simulate the formation of nanostructured materials by cluster beam deposition. Clusters are modelled by spherical balls with a given size distribution function, which fall to the substrate and stick to the growing structure. The mobility of clusters along the film surface is modelled by introduction of a critical angle at which a falling ball meets a ball that belongs to the structure. When the falling ball touches one of the balls in the structure at an angle smaller than the critical one, it sticks to the film; otherwise the ball rolls along the surface till it meets other balls. It is shown that a variety of structures similar to those observed experimentally can be produced. The density of the model structures, percolation thresholds and the surface roughness are analyzed.
\end{abstract}

Key words: nanomaterials, percolation, fractals, roughness exponent

PACS: $61.43 .-j, 61.46 .+w, 68.35 . B s, 68.35 . C t$

\section{Introduction}

Recently nanostructured materials have attracted much attention because of their unusual structural, electronic and mechanical properties. Among the variety of methods of synthesis of nanostructured materials, the cluster beam deposition seems to be very promising especially in thin film production [1]. Several authors have suggested that the assembling of carbon clusters can be used to produce a new class of porous materials with interesting functional properties [2-5]. Depending on the energy and size distribution of incident clusters, a large variety of morphologies of the films can be obtained. It should be noted, that the structure of these materials has little in common with usual amorphous structures or with the dense random packing of spheres, to say nothing of crystals. The cluster-assembled materials represent a new class of random structures, which is interesting not only from the point of view of possible applications, but also as a unique topological object. 
Experimental characterization and theoretical simulation of cluster-assembled materials face the problem of cluster organization in structures with length scales ranging from nanometers to micrometers [6]. In real conditions of experiments, clusters of different shapes and sizes fall to a substrate. The structure of the formed layer depends on the size distribution function, on the energy of depositing clusters, as well as on the kinetics of local processes when clusters join the structure. Molecular dynamics simulations of carbon cluster beam deposition [7] based on the many-body Tersoff interaction potential [8], have shed some light on the growth mechanisms leading to the formation of a nanostructured film and on the relation between the physical properties of the grown films and the beam features. In particular, it has been demonstrated that the film structure and porosity depend on the distribution function of incident clusters and on the deposition energy. The MD simulation is a powerful method which can be used for the investigation of elementary processes of the cluster impingement with the growing structure and the cluster attachment to the structure. However MD method has well-known restrictions. For example, in the massive MD simulation [7] approximately $10^{4}$ carbon atoms were deposited, which means that the number of clusters was less than several hundred. Obviously, this number of clusters is not sufficient for statistical analysis of the film structure and the surface roughness.

To overcome these difficulties and to be able to promptly create large and statistically representative structures we propose a "geometrical" model of cluster beam deposition. The main goal is to develop the methods of characterization of nanostructured porous materials and to investigate which parameters control the statistical properties of the obtained structures.

The paper is organized as follows: in the next section we describe in detail the algorithm of structure construction; then we analyze the properties of the modelled structures and conclude with the summary of the major results.

\section{The model}

We model the falling clusters using spherical balls with a given size distribution function. When the falling ball touches one of the balls in the structure at an angle smaller than the critical one, it stops. Otherwise, the ball rolls along the surface until it meets another ball.

Assume that we have $n$ types of balls with radii $R_{i}, i=1,2, \cdots, n$. The balls are falling one by one on a horizontal square base with the side $L$. Initial coordinates of the balls are generated randomly. The type of the ball is selected with the probability $p_{i}$, where $\sum_{i=1}^{n} p_{i}=1$. When the ball reaches the base it sticks to the base. The falling ball may meet a ball that belongs to the structure. In this case the ball rolls down the latter (figure 1). It is assumed that the balls do not penetrate into each other. The falling ball is added to the structure in the following cases:

1. The ball has reached the base (substrate); 
2. The ball has touched another ball and the angle $\alpha$ between the vertical line and the line connecting the ball centers is smaller than some critical angle $\alpha_{\mathrm{cr}}$ (figure 1);

3. The rolling ball has touched at least two balls of the structure.

The next falling ball is generated when the previous ball has joined the structure. The periodic boundary conditions are used in order to diminish the effect of the finite size of the system.

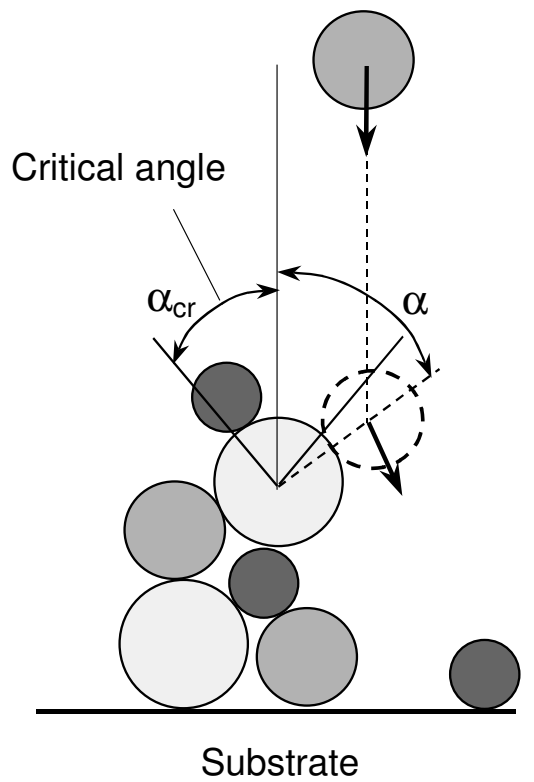

Figure 1. Schematic illustration of the ball structure construction.

The algorithm described above permits to construct various sufficiently large nanostructures with reproducible statistical properties. The critical angle can be viewed as a parameter connected with the mobility of real clusters impinging upon the film surface, i.e. the critical angle emulates the surface diffusion. To keep the model simple, in this paper the critical angle is assumed to be independent of the ball type. It is clear that in order to imitate the surface diffusion more accurately, the critical angle can be generated with a given probability distribution for each falling ball. Moreover, in principle, the probability distributions can be related to the properties of real carbon clusters (for example by means of MD simulations of relatively small pieces of carbon films).

The higher is the mobility of a cluster, the deeper it can penetrate into the nanostructure. This corresponds to small critical angles when the falling balls have a possibility to roll over, and only after frontal collisions the balls immediately stick to the structure. Stoppage of a ball when it touches two other balls corresponds to the formation of chemical bonds in a real situation of carbon clusters. A regime of low mobility of clusters is common, because deposition is usually performed on the substrates kept at low temperatures. The absence of mutual penetration of the balls means that the clusters do not shatter during collisions, i.e. the energy of the cluster beam is sufficiently small.

\section{Simulation results}

Figure 2 shows typical structures formed by deposition of the balls of three types. It is seen that the porosity depends on the critical angle of rolling. The loosest structures are formed if the impinging balls stop immediately when touching any ball belonging to the structure (figure 2a). The surface of the film deposited 
a

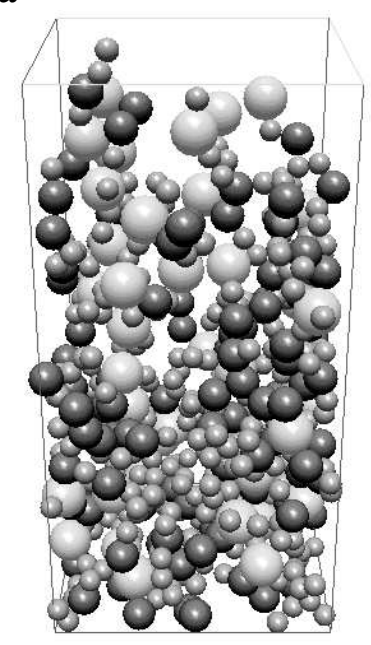

Critical angle $=\pi / 2$ $\mathbf{b}$

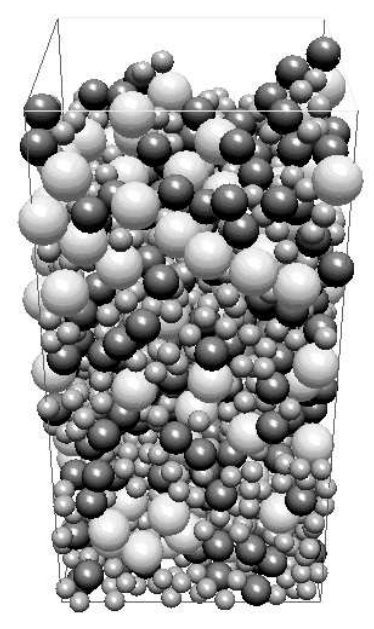

Critical angle $=0$

Figure 2. Fragments of structures simulated by deposition of the balls with the radii $R_{i}=1,1.5,2$; the corresponding probabilities $p_{i}=0.7,0.2,0.1$. Dimensions of the base are $25 \times 25$; the structure height is 50 .

at the critical angle $\alpha_{\mathrm{cr}}=0$ is quite flat. At the zero mobility of the impinging balls $\left(\alpha_{\mathrm{cr}}=\pi / 2\right)$, the film shows a disordered and highly corrugated surface with dendritic structures.

Experimentally, surface morphologies of nanostructured carbon-cluster-assembled films are characterized by an atomic force microscopy (AFM) operating with conical tips having a typical radius of curvature of $10 \mathrm{~nm}$ [9]. Following [9], by analogy with AFM investigations, in order to determine the geometrical boundaries of the external surface we scan the surface of the deposited ball structure with a probe ball of a given radius, which falls from the regular points $\mathbf{r}_{i j}=\left(x_{i}, y_{j}\right)$ from above onto the structure and sticks to it $\left(\alpha_{\mathrm{cr}}=\pi / 2\right)$. The spacing between the nearest scanning points is smaller than the radius of the probe ball. The coordinates of the center of the probe ball define the film surface (figure 3) and are used to calculate the height-height correlation function of the surface corrugation

$$
C(\mathbf{r})=\left\langle\left[h\left(\mathbf{r}+\mathbf{r}^{\prime}\right)-h\left(\mathbf{r}^{\prime}\right)\right]^{2}\right\rangle^{1 / 2}
$$

where $h(\mathbf{r})$ is the surface height. Angular brackets stand for the averaging over the points $\mathbf{r}_{i j}^{\prime}$. For fractal self-affine structures, the correlation function depends on the length $r=\sqrt{x^{2}+y^{2}}$ and has the following asymptotic behavior:

$$
C(r)=\left\{\begin{aligned}
r^{\alpha}, & r \ll \xi \\
\sqrt{2} \sigma, & r \gg \xi
\end{aligned}\right.
$$

where $\alpha$ is the roughness exponent, $\xi$ is the lateral correlation length and $\sigma$ is the standard deviation

$$
\sigma=\left\langle[h(\mathbf{r})-\langle h(\mathbf{r})\rangle]^{2}\right\rangle^{1 / 2}
$$



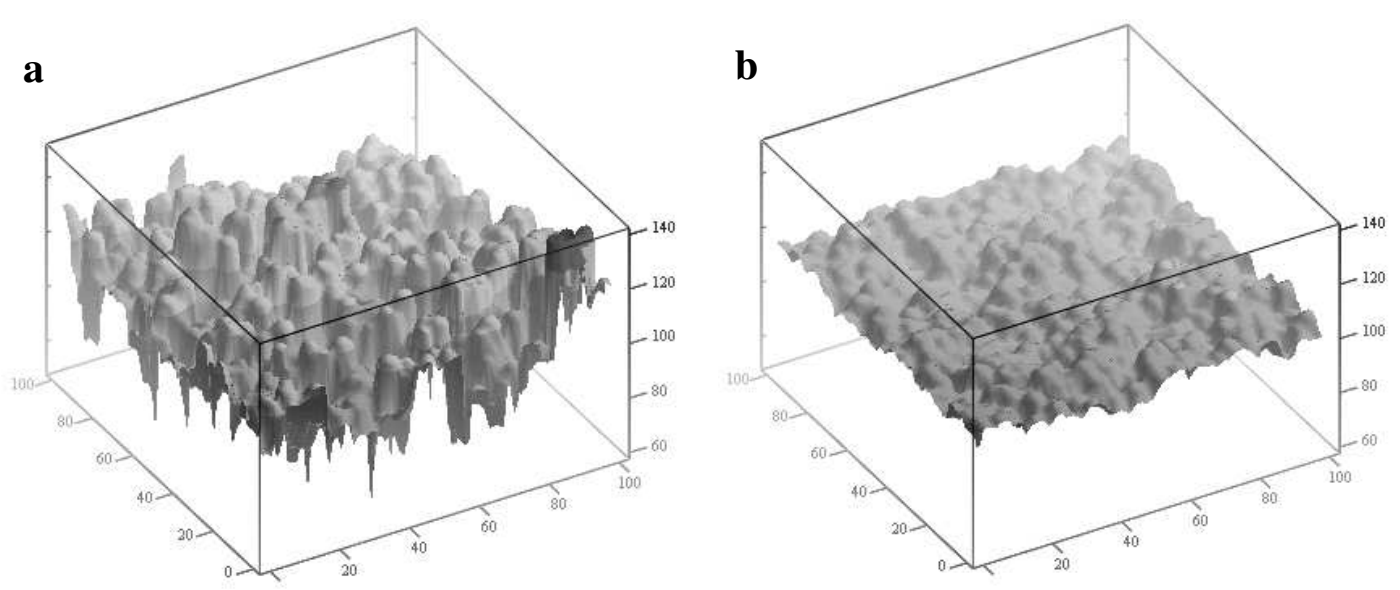

Figure 3. Images of the film surface scanned with the probe ball of the radius $R=1$. The structure was formed by deposition of the balls of two types $(R=1$ and 2, corresponding probabilities $p=0.8$ and 0.2 ) onto the substrate $L \times L=$ $500 \times 500$. The mean structure height is 100 . Here, fragments of $L \times L=100 \times 100$ are shown. The topography of the surfaces resembles the topography of real films produced by deposition of low energy carbon clusters [6]. The critical angle equals to $\pi / 2(\mathrm{a})$ or 0 (b).

The height-height correlation function has been calculated for the structures formed by the balls of one type and for the structures formed by the balls of two types (figure 4) at different critical angles. In both cases we have used the same radius of the probe ball, $R=1$, and the same size of the scanning mesh, $\Delta x=\Delta y=0.5$. It is seen that a well-defined power law exponent is observed, ranging from 0.45 to 0.6 , which depends on the critical angle (figure 4). These values can be compared with the experimental values of the roughness exponent $\alpha=0.64-0.68$ [10] measured in the structures obtained by deposition of low-energy carbon cluster beams ( $E_{\text {beam }}$ $<0.5 \mathrm{eV} /$ atom) which contained the clusters in the form of linear chains, closed rings and fullerenelike cages.

As it can be expected the surface roughness, $\sqrt{2} \sigma$, decreases with the critical angle decreasing (figure 5). At the same time the surface roughness increases with structure height:

$$
\sigma(\langle h\rangle) \propto\langle h\rangle^{\beta}
$$

where $\beta=0.11$ to 0.26 (figure 6 ). The increase of the surface roughness with the increase of the film thickness (or the deposition time) is an interesting property of nanostructured materials in view of a possible application as supercapacitors. The maximum value $\beta=0.26$ is attained if the falling balls stop immediately when touching any ball belonging to the structure $\left(\alpha_{\mathrm{cr}}=\pi / 2\right)$. As distinct from the ball model, in the lattice model of deposition (similar to that described in [11]), when the film surface has only a fixed number of sites available for the arriving structural elements, the surface roughness increases with the exponent $\beta=0.50$. Indeed, let the growing film have $N$ surface sites to which new structural elements can attach. 

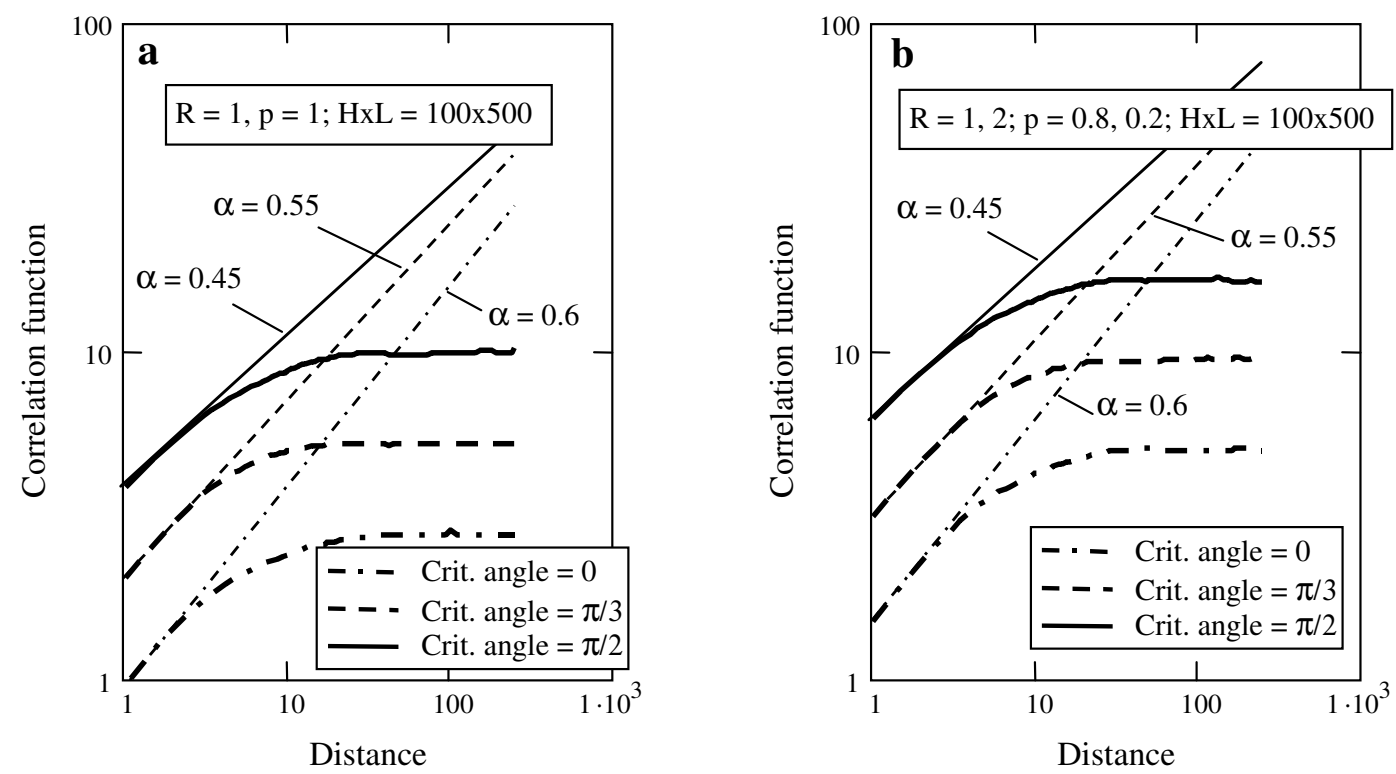

Figure 4. Correlation function versus distance for films grown from the balls of one type (a) and two types (b). The values of roughness exponent change in the interval from 0.45 to 0.6 , depending on critical angle. The substrate size is $L \times L=500 \times 500$. The mean structure height is 100 .
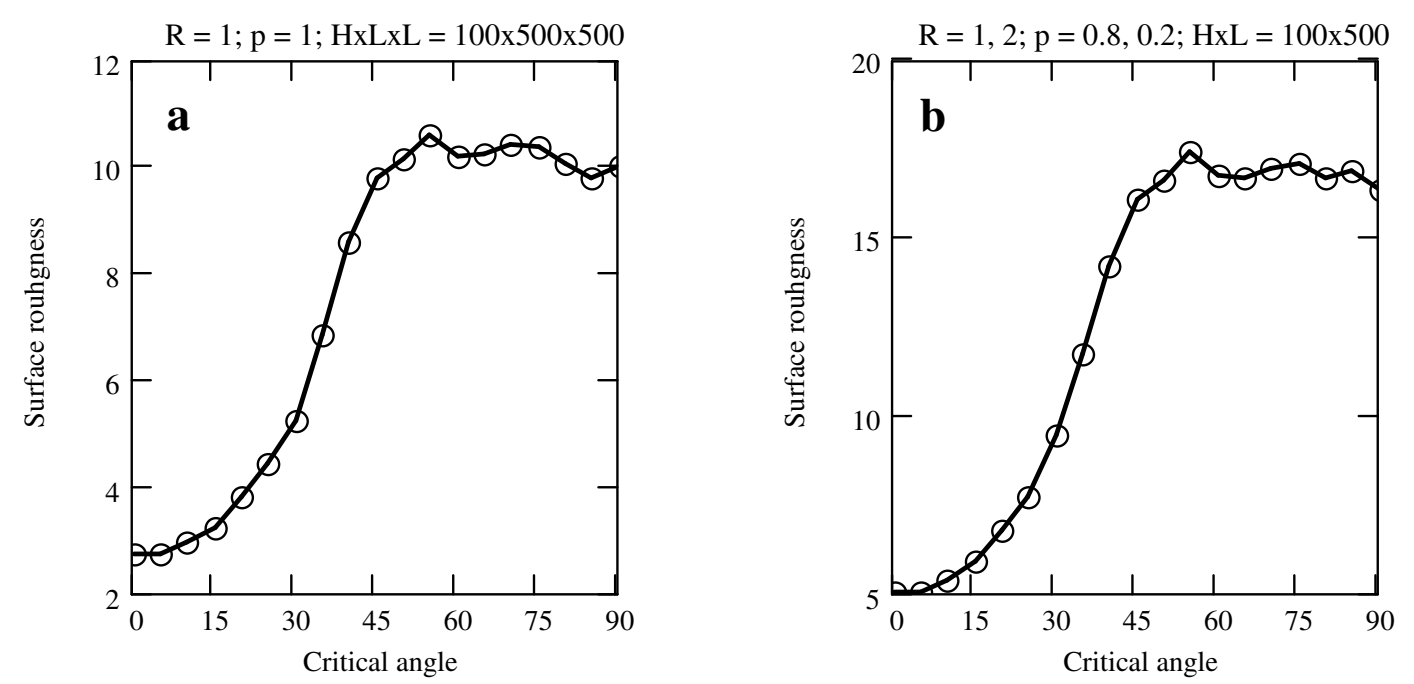

Figure 5. Dependence of the surface roughness $\sqrt{2} \sigma$ on critical angle for films grown from the balls of one type (a) and two types (b). The substrate size is $L \times L=500 \times 500$. The mean structure height is 100 . 

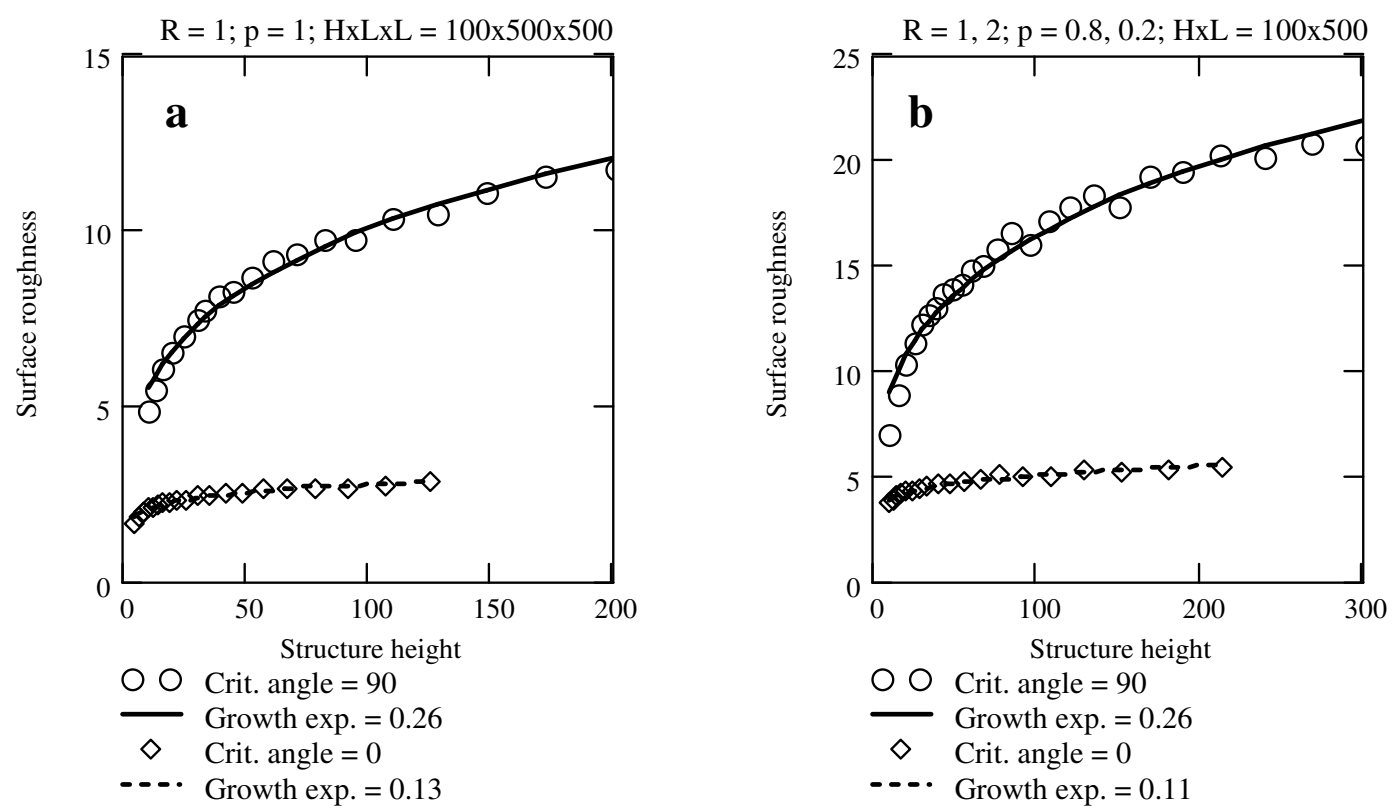

Figure 6. Dependence of the surface roughness $\sqrt{2} \sigma$ on the mean film thickness for films grown from the balls of one type (a) and two types (b). The substrate size is $L \times L=500 \times 500$.

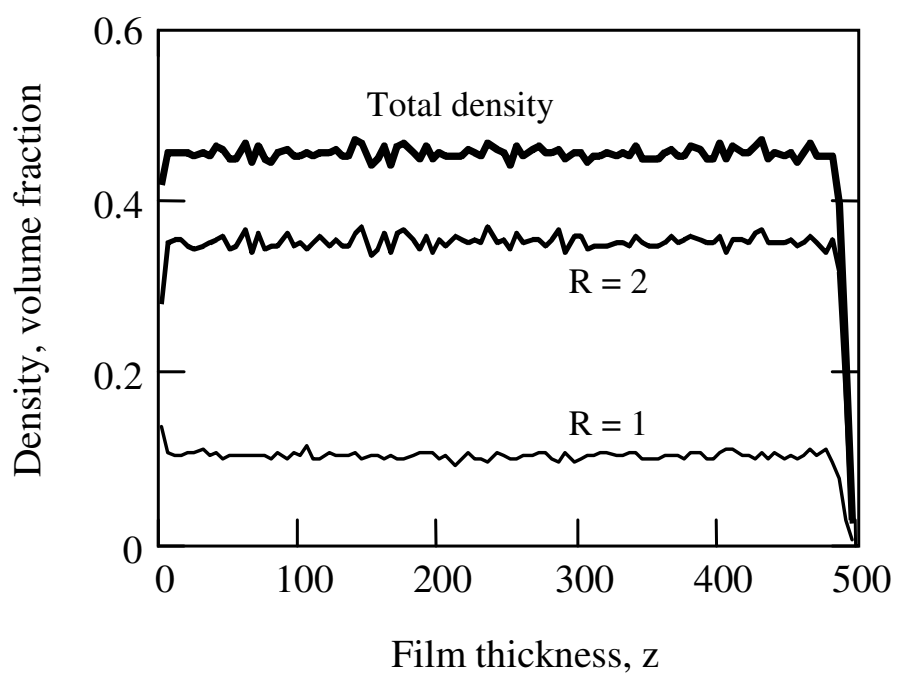

Figure 7. Dependence of the film density on the distance from the substrate. The balls of two types $R=1$ and $R=2$ with corresponding probabilities 0.7 and 0.3 were deposited on the base with dimensions $100 \times 100$. Critical angle is equal to 0 . The density was found by averaging over the layers of thickness 5 . 

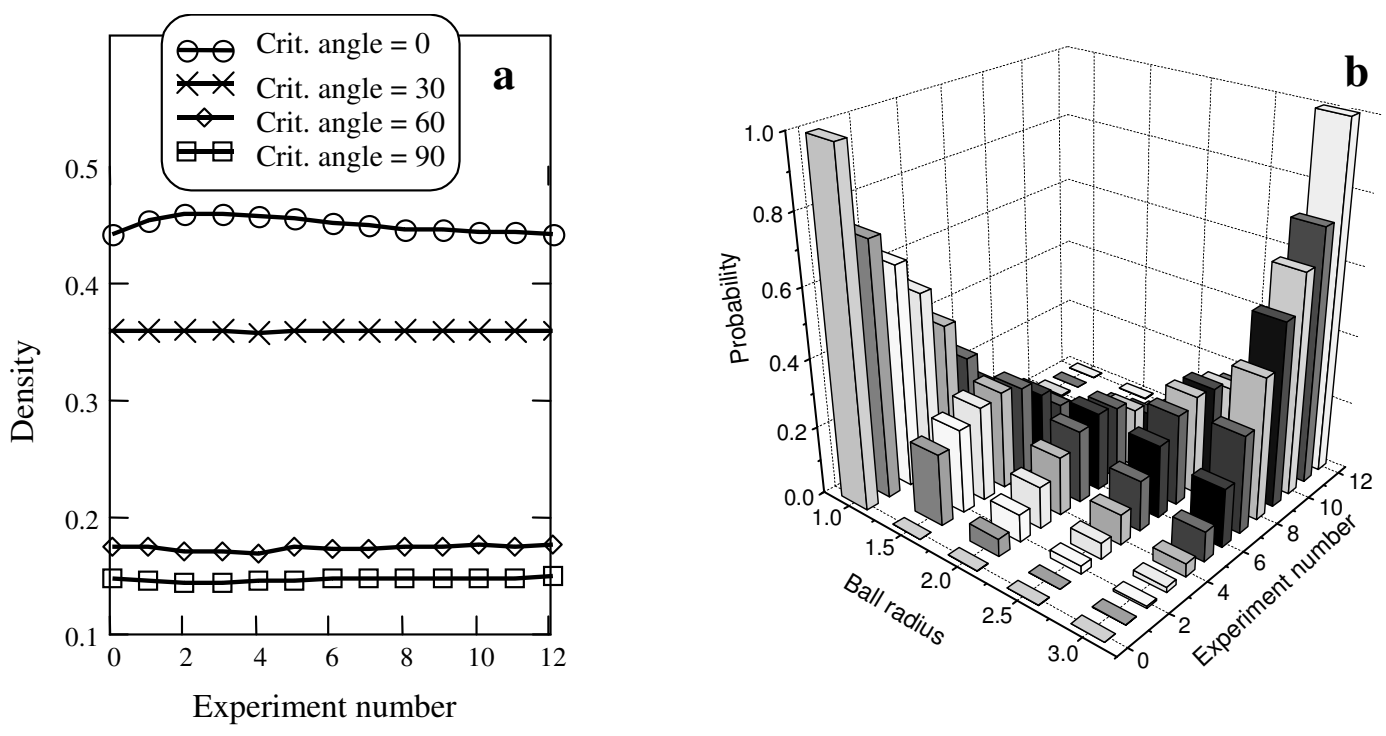

Figure 8. Dependence of film density (a) on distribution function of falling balls, which is indicated by corresponding computer "experiment numbers" (b).

Random stacking of $M$ elements $(M>N \gg 1)$ over $N$ sites produces the structure with the mean height $h_{L}$ and the standard deviation $\sigma_{L}$

$$
\begin{aligned}
& h_{L}=\sum_{k=0}^{M} k C_{M}^{k}\left(\frac{1}{N}\right)^{k}\left(1-\frac{1}{N}\right)^{M-k}=\frac{M}{N} \\
& \sigma_{L}^{2}=\sum_{k=0}^{M}\left(k-h_{L}\right)^{2} C_{M}^{k}\left(\frac{1}{N}\right)^{k}\left(1-\frac{1}{N}\right)^{M-k}=\frac{M}{N}\left(1-\frac{1}{N}\right),
\end{aligned}
$$

where $C_{M}^{k}$ is the binomial coefficient. Equation (6) means that $\sigma_{L} \propto \sqrt{h_{L}}$. In the ball model the number of available sites is unlimited. Therefore, the falling balls, joining the structure, screen some pits and valleys on the film surface. These pits and valleys become inaccessible for the scanning ball. Thus, the screening results in the formation of pores inside the structure and in a decrease in $\beta$ as compared to the lattice model. It should be noted that the synthesized cluster-assembled carbon films exhibit the exponent $\beta=0.42-0.50$ [10], which is larger than that obtained in our simulations. Probably, this indicates that there exist correlations in the attachment of depositing clusters to the film, which disable some available sites. One of the origins of the correlations is the covalent nature of the bonds between the carbon atoms.

Due to the fractal-like subsurface layer, the density of the ball structure depends on the distance from the substrate. In figures 7, 8 and 9 the densities of the structures formed at different critical angles are depicted. The density is defined here as a fraction of volume occupied by the balls. Figure 7 shows the dependence of density on the distance from the substrate. It is seen that the film is uniform in the central region. The density changes near the open surface having a fractal-like structure. 

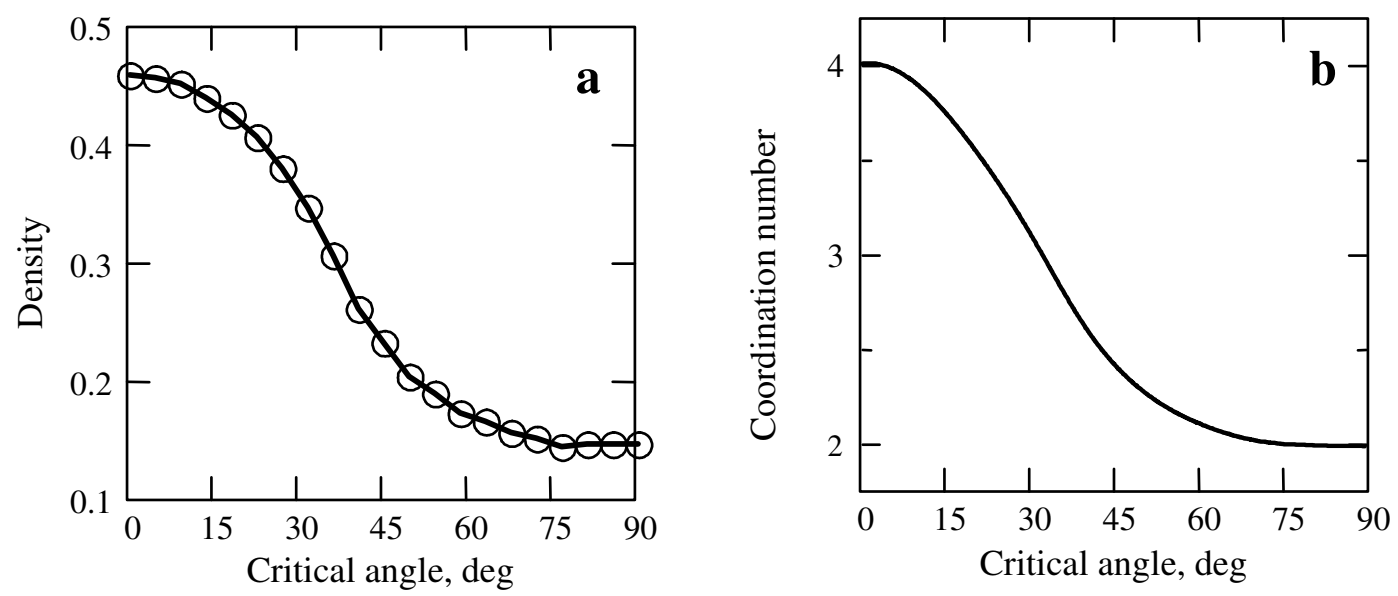

Figure 9. Density of structures formed by the balls at different critical angles (a) and average number of the nearest neighbors for a ball in the structure formed by the balls of one type as a function of critical angle (b).

We have found a remarkable universal property of the structures grown using our method - at the fixed critical angle the volume fraction occupied by the balls almost does not depend on the size distribution of the balls, i.e. the density of the structure depends only on critical angle. Examples illustrating this property are presented in figure 8 . The maximum density of the structures is about 0.45 . It is less than the density of random close packing of equal balls, $0.637[12,13]$. Our results suggest that the most dense film is formed when the volume fractions of different balls are the same, i.e. $p_{1} R_{1}^{3}=p_{i} R_{i}^{3}, i=1, \ldots, n$. The dependence of density on critical angle is plotted in figure $9 \mathrm{a}$. As it can be expected the coordination number of a chosen ball in the structure (the average number of the nearest neighbors) decreases with the increasing critical angle (figure 9b).

In real situation, the properties of structural elements (in our case, balls) may differ, resulting in the dependence of macroscopic properties on concentrations of structural elements. The elements of a given type may form connected clusters, which are defined as groups of the nearest neighbors. The size distribution of clusters (number of balls in clusters) depends on ball concentrations, $p_{i}$, and their radii, $R_{i}$. At some probability, the balls of a given type may form a percolating cluster that spans from bottom to top of the ball structure. To find the percolating cluster we cut bottom and top layers of the ball structure and analyzed the interior of the structure, where the balls of different types are distributed uniformly.

The onset of percolation has been investigated for the structures formed by conducting and by insulating balls having the same radii. Figure 10 shows the threshold value of concentration of conducting balls, at which the percolating cluster is formed as a function of the mean coordination number. In figure 10 we also compare our results with the power law proposed in [14] for site percolation thresholds for lattices at dimensions higher than two

$$
p_{\mathrm{c}}=1.2868((d-1)(q-1))^{-0.616},
$$




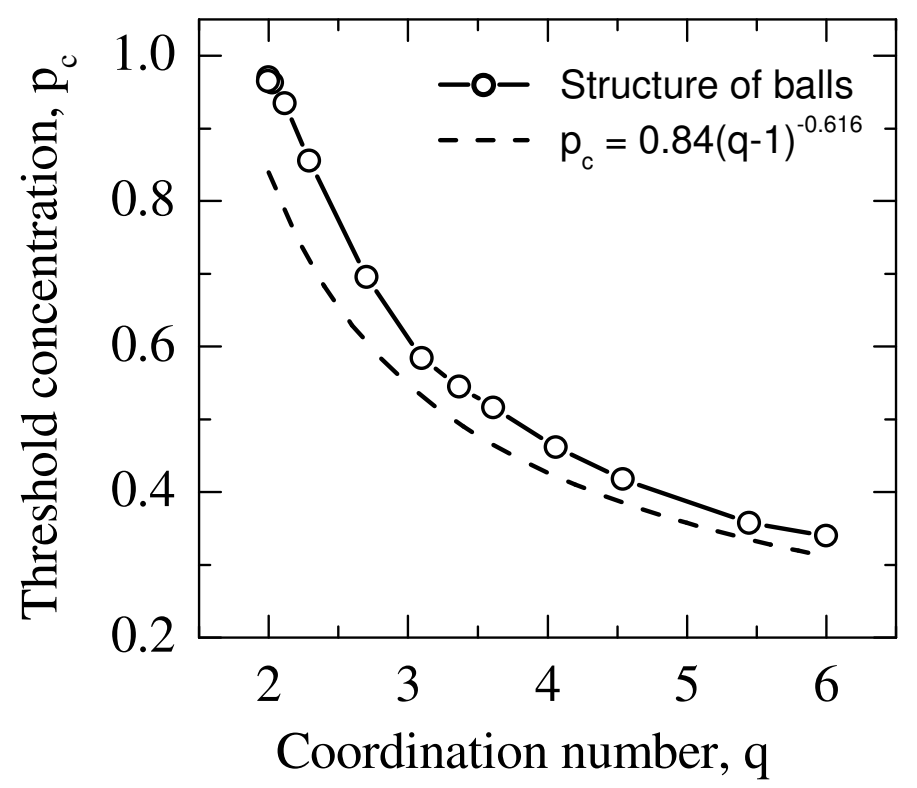

Figure 10. The threshold value of concentration of conducting balls required for percolation as a function of coordination number (the solid line). The dashed line shows the dependence of the site percolation threshold for regular lattices with different coordination numbers [14].

where $d$ is the dimension and $q$ is the coordination number. For the smallest coordination number $q=2$, that corresponds to loose structures $\left(\alpha_{\mathrm{cr}} \rightarrow \pi / 2\right)$, the percolating cluster is formed only if all the balls are conducting i.e. at $p_{\mathrm{c}}=1$. In order to obtain dense structures and to find the dependence of the percolation threshold at large coordination numbers, the algorithm of structure building was modified: the falling ball was added to the structure if it had simultaneously touched at least three balls of the structure.

\section{Summary}

- We have described a model to simulate the formation of nanostructured materials which are produced by means of the cluster-beam deposition. A simple case has been considered when the atomic clusters are modelled by the balls with a given distribution function. The mobility of real clusters impinging upon the film surface is simulated by introduction of a critical angle. When the falling ball touches one of the balls in the structure at an angle smaller than the critical one, it sticks to the film. Otherwise, the ball rolls along the surface until it meets another ball.

- The density of the ball structure monotonically decreases from 0.14 to 0.47 with the increase of a critical angle. At the same time, the density practically does not depend on the size distribution function of the falling balls. 
- The surface roughness increases with the structure height: $\sigma \propto\langle h\rangle^{\beta}$, where $\beta$ changes from 0.11 to 0.26 . The minimum value $\beta=0.11$ corresponds to the dense film $\left(\alpha_{\mathrm{cr}}=0\right)$.

- The percolation properties of the simulated ball structures have been investigated. For the structures formed by the balls of equal radii the dependence of the threshold concentration of conducting balls on coordination number is very similar to that for the case of regular lattices.

- The obtained results qualitatively agree with the experimental data on synthesis of nanostructured films by deposition of carbon clusters.

\section{References}

1. Milani P., Iannotta S. Cluster Beam Synthesis of Nanostructured Materials. Berlin, Springer, 1999.

2. Paillard V., Melinon P., Dupuis V., Perez J.P., Perez A., Champagnon B. // Phys. Rev. Lett., 1993, vol. 71, p. 4170.

3. Milani P., Ferretti M., Piseri P., Bottani C.E., Ferrari A., Li Bassi A., Guizzetti G., Patrini M. // J. Appl. Phys., 1997, vol. 82, p. 5793.

4. Benedek G., Colombo L. // Mater. Sci. Forum, 1996, vol. 232, p. 247.

5. Canning A., Galli G., Kim J. // Phys. Rev. Lett., 1997, vol. 79, p. 4442.

6. Milani P., Piseri P., Barborini E., Lenardi C., Castelnovo C., Podesta A. In: Nanostructured carbon for advanced applications (Eds. G.Benedek, P.Milani, V.G.Ralchenko), NATO Science Series, II Mathematics, Physics and Chemistry, vol. 24, 2001.

7. Donadio D., Colombo L., Milani P., Benedek G. // Phys. Rev. Lett., 1999, vol. 83, p. 776 .

8. Tersoff J. // Phys. Rev. B, 1989, vol. 39, p. 5566.

9. Bogana M., Donadio D., Benedek G., Colombo L. // Europhys. Lett., 2001, vol. 54, p. 72 .

10. Buzio R., Gnecco E., Boragno C., Valbusa U., Piseri P., Barborini E., Milani P. // Surf. Sci., 2000, vol. 444, p. L1.

11. Bakai A.S., Gonchar V.Yu., Krikun S.V., Lyubarskii G.Ya. // Functional materials, 1995, vol. 2, p. 222 (in Russian).

12. Feder J. Fractals. New-York, Plenum Press, 1988.

13. Ziman J.M. Models of Disorder. Cambridge, Cambridge University Press, 1979.

14. Galam S., Mauger A. // Phys. Rev. E, 1996, vol. 53, p. 2177. 


\section{Моделювання синтезу наноструктурних матеріалів, що утворюються при осадженні кластерів}

\section{М.С.Бишкін, О.С.Бакай, М.П.Лазарєв, А.А.Туркін}

Національний науковий центр Харківський фізико-технічний інститут 61108 Харків, вул. Академічна, 1

Отримано 29 січня 2003 р.

Описано модель утворення наноструктурних матеріалів при осадженні кластерних потоків. Кластери сферичної форми з заданою функцією розподілу за розмірами падають і прилипають до структури, що росте на підкладці. Ймовірність прилипання контролюється критичним кутом скочування по поверхні структури. Показано, що можна отримати різноманітні структури подібні до тих, що спостерігаються експериментально. Щільність структур, пороги протікання, поверхнева шорсткість досліджуються в залежності від параметрів моделі.

Ключові слова: наноматеріали, протікання, фрактали, показник шорсткості

PACS: $61.43 .-j, 61.46 .+w, 68.35 . B s, 68.35 . C t$ 